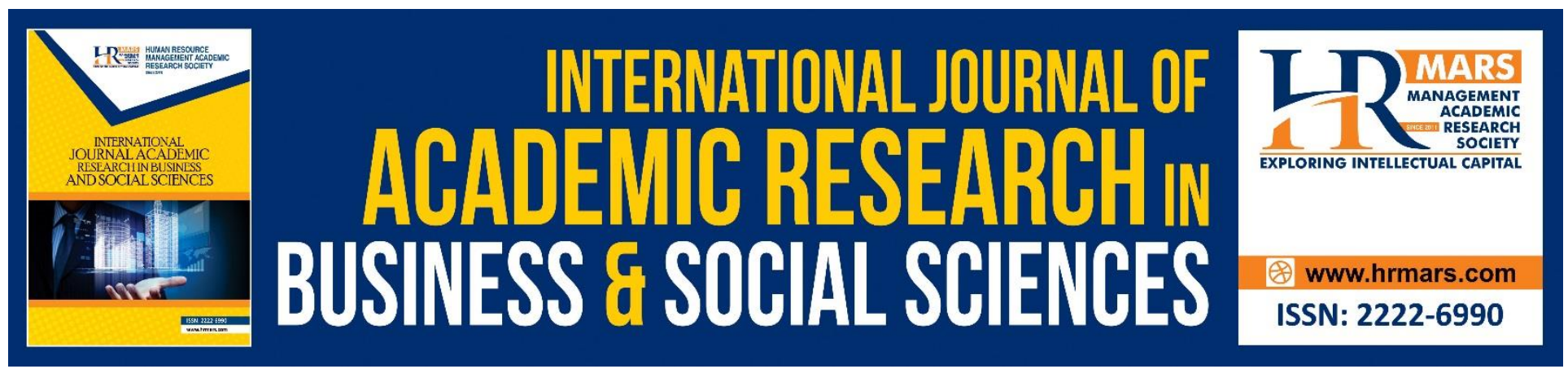

\title{
Parenting Styles as the Factor that Encourage Sharing Behavior among Preschoolers
}

\section{Samihah Binti Mahamud, Fong Jia Yean}

To Link this Article: http://dx.doi.org/10.6007/IJARBSS/v8-i9/4878

DOI: $\quad 10.6007 /$ IJARBSS/v8-i9/4878

Received: 29 August 2018, Revised: 16 Sept 2018, Accepted: 29 Sept 2018

Published Online: 09 October 2018

In-Text Citation: (Mahamud \& Yean, 2018)

To Cite this Article: Mahamud, S. B., \& Yean, F. J. (2018). Parenting Styles as the Factor that Encourage Sharing Behavior among Preschoolers. International Journal of Academic Research in Business and Social Sciences, 8(9), 1999-2007.

\section{Copyright: (c) 2018 The Author(s)}

Published by Human Resource Management Academic Research Society (www.hrmars.com)

This article is published under the Creative Commons Attribution (CC BY 4.0) license. Anyone may reproduce, distribute, translate and create derivative works of this article (for both commercial and non-commercial purposes), subject to full attribution to the original publication and authors. The full terms of this license may be seen

at: http://creativecommons.org/licences/by/4.0/legalcode

\section{Vol. 8, No. 9, September 2018, Pg. 1999 - 2007}

Full Terms \& Conditions of access and use can be found at http://hrmars.com/index.php/pages/detail/publication-ethics 


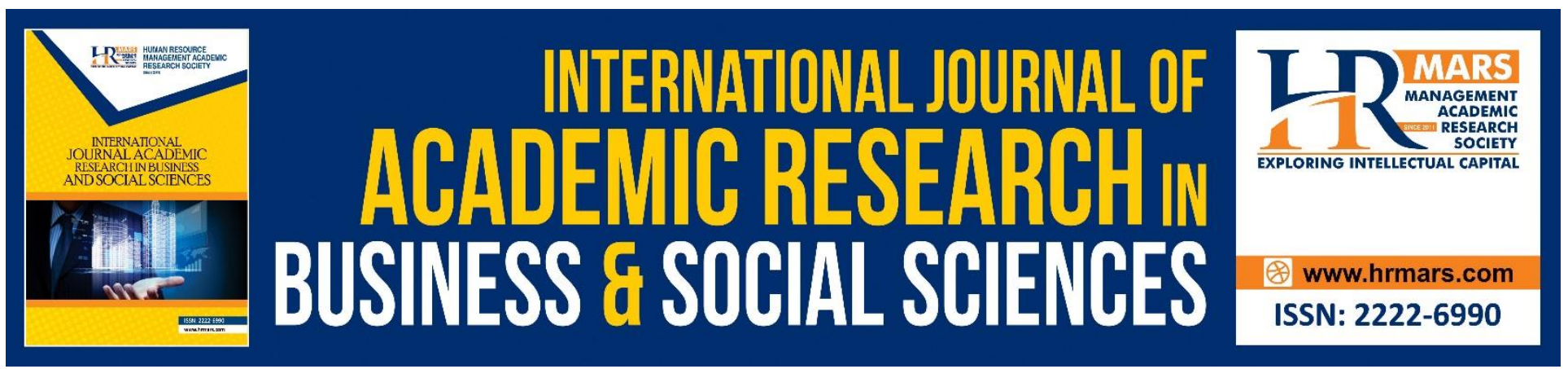

\title{
Parenting Styles as the Factor that Encourage Sharing Behavior among Preschoolers
}

\author{
Samihah Binti Mahamud \\ UNITAR International University, Malaysia \\ Fong Jia Yean \\ UNITAR International University, Malaysia
}

\begin{abstract}
The purpose of this study is to analyze the parenting styles as the factor that encourage sharing behavior among preschoolers. This study is important since the findings will create awareness to the parents on the importance of practicing a good parenting style in nurturing the children's sharing behavior. This study has adopted the qualitative research design. The primary data has been collected through semi-structured interview. The interview method used to obtain more information on this matter. The participants of this study are the parents that were purposefully chosen at some area in Puchong, Selangor. The research found that the authoritative parenting style able to encourage children's sharing behavior. The freedom given by parents would allow children to explore and develop sharing behavior. Parents and children interaction would make the children learn about valuable social skills while developing their prosocial behavior. The parents that practice authoritative style always encourage their children to share resources with others. The children will be willing to share when they observe their parent practice and show the same behavior. It is important to have a culture of sharing since it will be the foundation in shaping the children's sharing behavior.

Keywords: Parenting Styles, Authoritative Parenting Styles, Factor, Sharing Behavior, Preschoolers.

\section{Introduction}

Nowadays, we rarely observe children embrace the idea of sharing. Most of them prefer materials ownership compared to share with others. Do you know that sharing behavior is important skills for preschoolers as it is part of prosocial behavior? It is important to develop the sharing behavior among children particularly the preschoolers. According to the universal children developmental milestones, at the age of 5 to 6 , preschoolers are able to embrace the idea of sharing. Sharing behavior will shape a child's character to become a person with good personality. Besides, sharing behavior is an important skill that children need throughout their childhood and carry into adulthood.
\end{abstract}


Other than helping and cooperating, sharing is one of the behaviors that included in prosocial behavior. Prosocial behavior refers to the behavior that benefits another person or animal (Marion, 2007). Prosocial Behavior occurs in response to the well-being of other and carried out as response to noticed needs. Parents as the first agent of socialization to children would play an important role to guide children with positive character. The parents' influence on the child's character is very crucial in development of positive personality.

The objective of this study is to analyze the parenting styles as the factor that encourage sharing behavior among preschoolers. The study also could create awareness to parents on the importance of their parenting styles to nurture children's sharing behavior.

\section{Sharing Behavior}

Marion (2007) refers sharing as to divide, give and bestow. The things that people can always share are like materials information and their belongings. This kind of sharing behavior often observed by parents and teachers since children able to recognize that someone need the things and they would like to share it with friends. Sharing behavior is an important life skill that need to be learned by children. Sharing is a way that children learn to make friends and play cooperatively. Sharing is an important skill to help children in nurturing positive behavior.

According to Malti (2016), moral development describes the emergence and changes in an individual's understanding and feelings about moral principles across the lifespan. Morality includes various dimensions, most prominently emotions, knowledge and reasoning, values, and prosocial behaviors (Malti, 2016). Early moral development is an important foundation for prosocial behavior. The most prominent contribution theory to understanding of children's moral development has been made by Jean Piaget (Nazar, 2001). Piaget refers to a level of moral development in action that precedes heteronomous and autonomous moral reasoning. This action levels allows children to begin to interact with people and objects (Hammond S. 2014).

Prosocial behavior is defined as a behavior that is primarily aimed at benefiting others. The scope of prosocial behavior encompasses different behavioral elements including sharing, helping, comforting, empathy, sympathy, compassion, concern, volunteering, donating and cooperating (Emagnaw \& Hong, 2018).

\section{Parenting Styles}

Parenting style refers to the method that parents choose to practice in educating and raising the children. There are four types of parenting style include authoritative, authoritarian, permissive and uninvolved or neglectful. Parenting style is an important factor in children's socio-emotional development. Diana Baumrind found that parental responsiveness and parental demandingness are the two basic elements to shape successful parenting. 


\section{Demandingness}

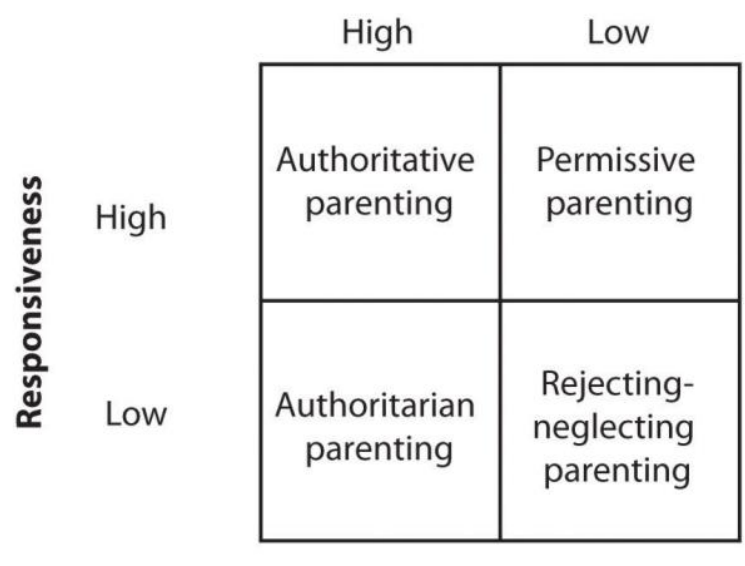

Figure 1. Two dimensions of parenting styles

(Sydney \& Trentzsch, S., 2014)

Baumrind D. in 1966 has identified three types of parenting style which is authoritative parenting, authoritarian parenting and permissive parenting. Then, in 1983 Maccoby and Martin had expanded Baumrind's parenting style theory and added uninvolved or neglectful parenting style which mostly being negative across all domain. Baumrind D. in 1966, believes that parenting style has impact on children's behavior. Parenting style is a determinant factor in the development of children and it would affect the social and psychological of children.

Children's prosocial behavior which inclusive of sharing behavior is longitudinally predicted by parenting style. Prosocial behavior being develop when the parents are warm, supportive and sensitive to the needs of children. However, when parenting style that are authoritarian, strict or punitive, the prosocial behavior nurture lesser (Knafo \& Israel, 2008). Therefore, it is important that the research conducted to examine whether the parenting style is the profound factor in encouraging sharing behavior. This happen because children raised by authoritative parents tends to have higher self-esteem, social skills and able to work well with others. 
INTERNATIONAL JOURNAL OF ACADEMIC RESEARCH IN BUSINESS AND SOCIAL SCIENCES Vol. 8, No. 9, Sept. 2018, E-ISSN: 2222-6990 @ 2018 HRMARS

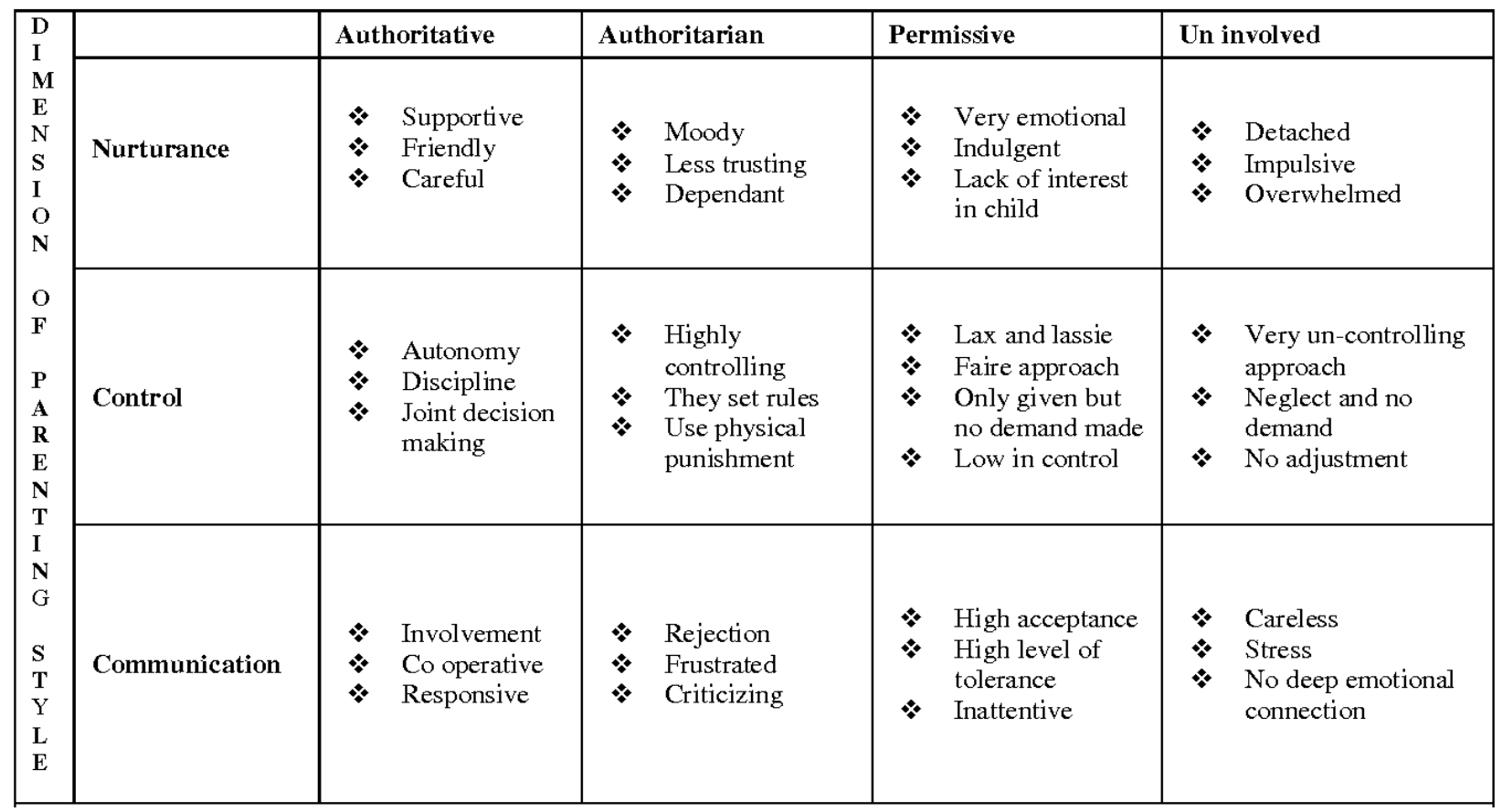

Figure 2. Characteristics of parenting styles and dimensions of parenting

(Sultana S. \& Ghose A., 2013)

Sharing behavior is essential for young children especially to preschoolers. Sharing is an important aspect of human cooperative activities during the early life of childhood. Therefore, it is important to study and focus on the factor encouraging the sharing behavior.

\section{Methodology}

This study has employed qualitative research methodology. The primary data has been collected through semi-structured interview with parents. The semi-structured interview with parents used seven open-ended questions. The qualitative interview occurs when researchers ask one or more participants general, open-ended questions and record their answers (Creswell, 2014).

The participants for this study are the parents that were purposefully selected at some area in Puchong area. In qualitative research, we identify our participants and site on purposeful sampling, based on places and people that can best help us understand our central phenomenon (Creswell, 2014). This study used purposive sampling technique to recruit five parents that have children aged 5 to 6 for the interview session.

The instrument for this study was the open-ended interview questions that has been used during the semi-structured interview session. The interview session that involving parents used seven openended questions. Some interview questions asked to the participant are like "Tell me about parenting styles that you know? One-on-one interview has been adopted for this study. The one-on-one interview is a data collection process in which the researcher asks questions to and records answers 
from only one participant in the study at a time (Creswell, 2014). The interview session has been carried out with parents where they were asked about their personal background and the factor encouraging sharing behavior which involve parenting styles.

Qualitative data analysis focuses on in-depth, context-specific, rich, subjective data and meaning by the participants in the situation, with the researcher himself/herself as a principle research instrument (Cohen, Manion \& Morrison, 2018). The data that had been recorded from the interview session were analyzed by hand. The hand analysis of qualitative data is when the researcher read the data, mark it by hand, divide it into parts (Creswell, 2014). The data were first organized and according a schematic recording system. The interview responds data were then transcribed. Transcription is the process of converting audiotape recordings or fieldnotes into text data (Creswell, 2014).

\section{Result and Discussion}

There are five parents were selected randomly to participate in the interview session. All of them think that parenting style is one of element that encouraging children to share between each other. Every parent has different perception on this matter. Three parents responded that authoritative parenting style can encourage children to share with others. There are two parents think that the authoritarian parenting style would be able to encourage children to share with others.

Parent A, B and D supported on authoritative parenting style has significant influence in encouraging children's sharing behavior. She claimed that it is important to give freedom for children to explore. By giving freedom to children, it would allow children to think freely and fulfil their needs. As a parent, she also using the same parenting style in educate her children. Authoritative parenting style more likely to define and determine rules associated with family, while encouraging to consider them as a resource (Sarwar, 2016).

Parents $C$ and $E$ supported on authoritarian parenting style. They claimed that it is important for parents to instruct and guide the children's behavior because children will always follow instruction. Therefore, parents and caregiver need to be strict in educating children. Besides, she said that parents and caregiver need to always remind them to share. Authoritarian parenting style is considered to be forceful, corrective and believes that children should adhere to work ethics and be obedient (Sarwar, 2016).

Overall, majority of the parents claimed that authoritative parenting style has the biggest impact on influencing children's sharing behavior. Parenting style practiced at home is important because the children learn things from home before they enter the school. Moreover, they also said that it is important to have a culture of sharing practiced at home to help children shape their good characters.

\section{Conclusion}

As the purpose of this study is to analyze the parenting styles as the factor that encourage sharing behavior among preschoolers, the study has been tailored to examine the best parenting style that 
INTERNATIONAL JOURNAL OF ACADEMIC RESEARCH IN BUSINESS AND SOCIAL SCIENCES Vol. 8, No. 9, Sept. 2018, E-ISSN: 2222-6990 (C) 2018 HRMARS

could encourage sharing behavior. The study also could create awareness to parents on the importance of practicing the best parenting styles to nurture children's sharing behavior.

In encouraging sharing behavior, parents are expected to practice authoritative parenting style because it has the characteristic to boost the children's readiness to share with others. Majority of the participants had agreed that when they practiced authoritative parenting style to their children, they notice that the sharing behavior is mostly shown in many situations. Children will embrace the idea of sharing because they have built the character of a confident child from their authoritative parents. Thus, they are aware and ready to share things with others and developed a better social skill.

Authoritative parenting style is assertive in communication and set a clear standard of behavior for their children. The authoritative parents are supportive and understanding on their children's need and idea. According to Sarwar S. (2016), parents of this type will provide guidance to their children and encourage verbal give and take while express reasoning. Good parents will educate their children with authoritative style and always encourage their children to share. They will buy extra things for their child to share with other children.

Parenting style is another element that facilitate the children's' learning. One of the factors that influence children character development is determined by how their parents teach and interact with them. Children spent tons of time at home with parents. The experience that the children have at home would determine their characters in the future.

As a suggestion for future research, researcher may work on discovering the importance of practicing the right parenting style in shaping the children positive character and personality. Other than that, a research could be conducted in finding the relationship between different parenting styles i.e; the authoritative parenting styles, authoritarian parenting styles, permissive parenting styles and neglectful parenting styles and the other elements of prosocial behavior such as helping, comforting, empathy, compassion, concern, volunteering, donating and cooperating.

\section{References}

Cohen L., Manion L. \& Morrison K. (2018). Research methods in education $8^{\text {th }}$ ed. Glasgow, Great Britain, Routledge.

Creswell J. W. (2014). Educational research: Planning, conducting and evaluating quantitative and qualitative research $4^{\text {th }} \mathrm{ed}$. Edinburgh, Pearson.

Emagnaw, A. B. \& Hong, J. (2018). Relationship among Parenting Styles, Prosocial Behavior and School Performance of Students Who are Attending to Grade Seven and Eight State Schools. Journal of Sociology and Anthropology. 2(2), 44-50. 
INTERNATIONAL JOURNAL OF ACADEMIC RESEARCH IN BUSINESS AND SOCIAL SCIENCES

Vol. 8, No. 9, Sept. 2018, E-ISSN: 2222-6990 (C) 2018 HRMARS

Harrigan, W., \& Commons, M. (2015). Replacing Maslow's needs hierarchy with an account based on stage and value. Behavioral Development Bulletin, 20(1), 24-31. http://dx.doi.org/10.1037/h0101036

Hammond, S. (2014). Children's Early Helping in Action: Piagetian Developmental Theory and Early Prosocial Behaviour. Frontiers in Psychology, 5(759). Retrieved from https://www.researchgate.net/publication/264642561_Children's_Early_Helping_in_Action_Pi agetian_Developmental_Theory_and_Early_Prosocial_Behavior

Knafo, A., \& Israel, S. (2008). Genetic and Environmental Influences on Prosocial Behavior. Retrievedfromhttps://www.researchgate.net/publication/238115339_Genetic_and_Environm ental_Influences_on_Prosocial_Behavior

Joseph M. V., John J. (2008). Impact of Parenting Styles on Child Development. Global Academic Society Journal: Social Science Insight. 1(5), 16-25.

Joseph H. W., \& Lamport C. M. (2015). Replacing Maslow's Needs Hierarchy with an Account Based on Stage and Value (1st ed., pp. 24-31). American Psychological Association. Retrieved from http://web.b.ebscohost.com.proxy.unitar.my:8080/ehost/pdfviewer/pdfviewer?vid=4\&sid=fbb bcb85-4716-4ed1-93e0-ca80cc58baf7\%40sessionmgr101\&hid=130

Malti, T. (2016). The Moral Foundations of Prosocial Behaviour. Prosocial Behaviour, 27-31. Retrieved from http://www.child-encyclopedia.com/sites/default/files/dossiers-complets/en/prosocialbehaviour.pdf

Marion, M. (2007). Guidance of Young Children (7th ed., pp. 250-271). United State: Pearson. McLeod, S. (2014). Vygotsky / Simply Psychology. Simplypsychology.org. Retrieved 18 May 2017, from https://www.simplypsychology.org/vygotsky.html

Nazar, F. (2001). Moral Judgement of Preschool Kuwaiti Children. International Education Journal, 2(6), 116-122. Retrieved from http://www.flinders.edu.au/education/iej

Sarwar, S. (2016). Influence of parenting styles on children's behavior. Journal of Education and Educational Development. 3(2), 222-249.

Sydney \& Trentzsch, S. (2014). A Parent's Guide to Parenting. Developmental Psychology at Vanderbilt. Retrieved from https://my.vanderbilt.edu/developmentalpsychologyblog/2014/04/a-parents-guide-toparenting/

Sultana S. \& Ghose A. (2013). Construction of a Scale on Perceived Parenting Style. Retrieved 
INTERNATIONAL JOURNAL OF ACADEMIC RESEARCH IN BUSINESS AND SOCIAL SCIENCES

Vol. 8, No. 9, Sept. 2018, E-ISSN: 2222-6990 @ 2018 HRMARS

from https://www.semanticscholar.org/paper/Construction-of-A-Scale-On-PerceivedParenting-Sultana-Ghose/6534749eeddf30fc6ef76fa8692d0d7762b4cde9 